\title{
Originals
}

\section{Hospital Admission Rates of Diabetic Children}

\author{
Janet Hardie ${ }^{1}$, K. McPherson ${ }^{2}$, and J. D. Baum ${ }^{1}$ \\ 1 Department of Paediatrics, University of Oxford, John Radcliffe Infirmary, and \\ 2 Department of Social and Community Medicine, University of Oxford, Oxford, England
}

Summary. In 1973 a children's diabetic clinic was established in Oxford. An analysis has been made of the effects this has had on the pattern of emergency admissions classified as severe hyperglycaemia (A), moderate hyperglycaemia (B) and hypoglycaemia (C). A comparison of the admission rate per "diabetic year" over the four years before and the three years after the children's clinic was established showed a significant decrease in admission rate for all hyperglycaemic admissions $(p<0.05)$. This decrease was shown to be mainly due to a reduction in admissions with severe hyperglycaemia $(\mathrm{A})(\mathrm{p}<0.01)$, there being no significant change in admission rate for moderate hyperglycaemia (B). There was no significant change in admission rate for hypoglycaemia (C).

Key words: Diabetes children, hospital admissions, hyperglycaemia, hypoglycaemia.

This study was undertaken in an attempt to measure, in terms of hospital admission rates, the effects of providing a specialist service for diabetic children.

\section{Methods}

\section{The Organisation of the Children's Diabetic Clinic}

Newly diagnosed diabetic children were stabilised in hospital and subsequently attended the clinic approximately three monthly. Control was monitored by: home urine tests for glucose recorded at least twice daily; by $24 \mathrm{~h}$ urine collections for glucose excretion performed every 3 to 6 months; by regular accurate measurements of height and weight; and by clinical indices of well-being. Children attended with one or both parents up to the age of 14 years, after which they were encouraged to come alone. Transfer to the adult diabetic clinic generally took place after the age of 16 years. A 24-hour 'phone-in' service was provided, and was used to the extent of two to three calls per day. Younger diabetic children were generally treated with an intermediate-acting insulin (Novo Monotard), in some cases with the addition of a short-acting insulin (Novo Actrapid), as a single daily injection for as long as control remained satisfactory as judged by clinical well-being, normal growth and a majority of home urine tests glucose-free. Children were sometimes changed to two injections daily (generally a combination of Novo Semitard and Actrapid insulins) during the pubertal years. The clinical staff included a consultant paediatrician with a special interest in diabetes, a clinical research fellow, a child psychiatrist, a community paediatric nurse, a dietitian and a laboratory technician.

\section{Analysis of Hospital Admission Rates}

Over a seven year period (October 1969 - October 1976) three categories of hospital admissions were studied:

A. Severe hyperglycaemia, as defined by an initial plasma bicarbonate $<9 \mathrm{mmol} / 1$ (mean $7.3 \mathrm{mmol} / \mathrm{l})$.

B. Moderate hyperglycaemia, as defined by plasma bicarbonate $>9 \mathrm{mmol} / \mathrm{l}($ mean $17.6 \mathrm{mmol} / \mathrm{l})$.

C. Hypoglycaemia severe enough for hospital admission.

The distinction between $\mathrm{A}$ and $\mathrm{B}$ admissions was made according to the definition of diabetic coma given in Joslin's Diabetes Mellitus [1]. In order to ensure that the division of Groups A and $B$ by plasma bicarbonate was in accord with the clinical severity of presentation they were also examined with respect to the level of consciousness of the children on admission to hospital. Admissions were divided into three categories according to level of consciousness as follows: coma, precoma and fully conscious. Children in coma were unrousable. Children in precoma were drowsy but responded to commands. Children classified as 'fully conscious' showed no disturbance of consciousness.

Admissions other than emergencies falling into categories A, B and $\mathrm{C}$ were not included in this study. Thus for example elective admissions for stabilisation or tooth extraction were not included.

Difficulties arose over analysing admission rates because of the steady expansion of the child diabetic population during the seven year study period. There were also difficulties because not all children were transferred simultaneously from the general paediatric clinics to the newly created diabetic clinic in 1973. The children's entry into the clinic was staggered over a period of about nine 
Table 1. A comparison of the admission rates for the periods before and after the establishment of the Children's Diabetic Clinic. Categories $\mathrm{A}, \mathrm{B}$ and $\mathrm{C}$ are defined in the text

\begin{tabular}{|c|c|c|c|c|c|}
\hline \multirow[b]{2}{*}{$\begin{array}{l}\text { Admission } \\
\text { Category }\end{array}$} & \multirow[b]{2}{*}{$\begin{array}{l}\text { 1969-1973 } \\
\text { Admissions }\end{array}$} & \multirow[b]{2}{*}{$\begin{array}{l}\text { 1973-1976 } \\
\text { Admissions }\end{array}$} & \multicolumn{2}{|c|}{$\begin{array}{l}\text { Admission rate per } \\
\text { diabetic year }\end{array}$} & \multirow[b]{2}{*}{$\mathrm{P}$} \\
\hline & & & $1969-1973$ & 1973-1976 & \\
\hline$A+B+C$ & 30 & 44 & 0.21 & 0.16 & NS \\
\hline $\mathrm{A}+\mathrm{B}$ & 26 & 30 & 0.19 & 0.11 & $<0.05$ \\
\hline A & 14 & 9 & 0.10 & 0.03 & $<0.01$ \\
\hline $\mathrm{B}$ & 12 & 21 & 0.09 & 0.07 & NS \\
\hline $\mathrm{C}$ & 4 & 14 & 0.03 & 0.05 & NS \\
\hline $\begin{array}{l}\text { Total } \\
\text { diabetic years }\end{array}$ & 140 & 284 & & & \\
\hline
\end{tabular}

(NS = not significant)

months. It was decided to express the data as 'admission rate per diabetic year'. This figure was obtained for the periods before and after entry into the diabetic clinic by dividing the sum of admissions for each child by the sum of the total duration of attendance of each child in the general paediatric clinics in Oxford (from 1.10.69) or in the children's diabetic clinic (from 1973 to 30.9.76) respectively.

The admission rate was calculated in this way for each category of admission A, B and C. This study does not include those few children who have continued to attend the general paediatric clinics or adult diabetic clinics in Oxford. New diabetics with a history of less than two months on the date of completion of the study $(1.10 .76)$ were also excluded from the study. All tests of significance were made using the chi-squared test.

\section{Results}

The mean blood glucose level on admission was significantly higher in Group A $(31.9 \pm 12.7 \mathrm{mmol} / \mathrm{l})$ than in Group B $(19.4 \pm 11.1 \mathrm{mmol} / \mathrm{l})(\mathrm{p}<0.001$ by Student $t$-test). Two episodes of coma were found among Group A admissions and none among Group B. Fifteen out of 23 patients in Group A were in precoma while only 7 out of 33 patients in Group B were in precoma.

There was no significant change in admission rate for all three categories of admission considered together $(\mathrm{A}+\mathrm{B}+\mathrm{C})$ (see Table 1$)$. There was a significant $(\mathrm{p}<0.05)$ decline in admission rate for both grades of hyperglycaemia considered together $(\mathrm{A}+\mathrm{B})$ but on further analysis the decline is seen to be due entirely to a highly significant $(p<0.01)$ decline in the admission rate for severe hyperglycaemia (A). There was no significant change in admission rate for the moderate category (B). There was no significant change in admission rate for hypoglycaemia (C).

The mean age of the children in the clinic on 1. 1.76 was 10.9 years $(S D \pm 3.6)$ which was signifi-
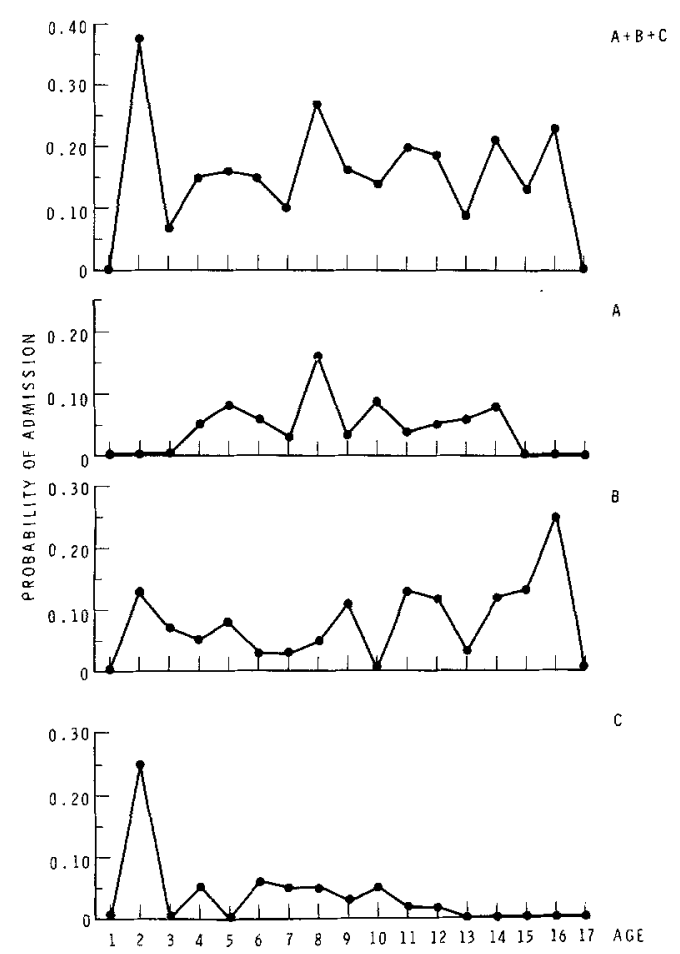

Fig. 1. The probability of admission according to age was derived by dividing the total number of admissions at each age by the total number of diabetic years at that age for each year from 1 to 17. In the graph the probability of admission is shown against age. A Severe hyperglycaemia (initial bicarbonate $<9 \mathrm{mmol} / 1$ ). B Moderate hyperglycaemia (initial bicarbonate $>9 \mathrm{mmol} / \mathrm{l}$ ). C Hypoglycaemia severe enough for hospital admission

cantly greater $(\mathrm{p}<0.01)$ than the mean age of the clinic population on 1.1 .72 (8.8 \pm 3.1 years). These dates were chosen as being roughly representative of the clinic periods I (1969 to 1973) and II (1973 to 1976). The probability of admission according to age is expressed graphically for each category of admission in Figure 1. Since the graph is based on small 


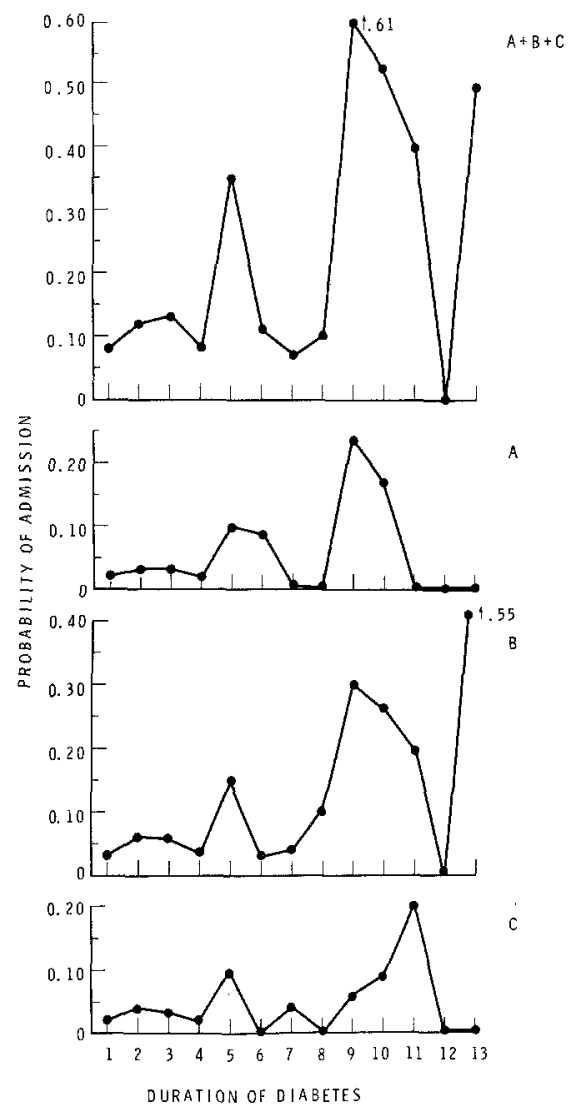

Fig. 2. The probability of admission according to duration of diabetes was derived by dividing the total number of admissions by the total number of diabetic years for each year of duration of diabetes from 1 to 12 years. In the graph the probability of admission is shown against duration of diabetes. A Severe hyperglycaemia (initial bicarbonate $<9 \mathrm{mmol} / \mathrm{l}$ ). B Moderate hyperglycaemia (initial bicarbonate $>9 \mathrm{mmol} / \mathrm{l}$ ). C Hypoglycaemia severe enough for hospital admission

numbers of patients, no undue importance should be attributed to individual peaks, particularly at the extremes of age; but it does show that there is no systematic relationship between age and probability of admission.

The mean duration of diabetes of children in the clinic on 1. 1.76 was $4.3 \pm 3.3$ years which is not significantly longer than that of children in clinics on 1. 1.72 , which was $3.5 \pm 2.5$ years. The probability of admission according to duration of diabetes is expressed graphically for each category of admission in Figure 2. It appears that the risk of admission in all three categories A, B and C increases with the duration of diabetes.

\section{Discussion}

An analysis of the rates of emergency admissions among diabetic children showed that since the estab- lishment of the Children's Diabetic Clinic in 1973 the number of admissions for more severe hyperglycaemia (A) has fallen significantly, but that admission rates for moderate hyperglycaemia (B) and for hypoglycaemia (C) have not changed significantly.

A retrospective study of this kind may clearly be subject to bias arising from several possible sources. The two clinic populations have been shown to differ significantly in respect of age but not duration of diabetes. Since there is no systematic relationship between age and probability of admission (Figure 1), the difference in mean age of the two clinic populations should not affect a comparison of their admission rates. However, the probability of admission does appear to increase with duration of diabetes (Figure 2). The reduction in $\mathrm{A}$ admissions during phase II cannot be explained on the basis of the mean duration of diabetes, since this was slightly longer in period II compared with period I.

Any change in admission rates must also be seen in the context of a general improvement in the standards of patient education and general practitioner care, which have probably taken place over the past seven years. These trends are likely to have been encouraged by the establishment of a special diabetic clinic whose facilities extend into the community. Laron [2] compared the effects of treatment by a multidisciplinary team which included a psychologist and a social worker with conventional treatment (by physician alone or with nurse) and found a number of positive influences. The degree of control was superior, there were fewer complications with no episodes of coma, brittle diabetes or severe ketoacidosis and also no need for hospitalisation. Other centres with specialised services for diabetic children have reported similar improvements in overall management but without data on admission rates [3].

There has been a change towards using purer porcine insulins over the past five years particularly in those patients who were previously on large daily doses of bovine or mixed porcine-bovine insulins. In 1972,40 out of 41 patients were taking conventional bovine insulin, while in 1976 only 18 out of 101 were still on conventional insulin. The risk of hypoglycaemic attacks attendant upon a change from conventional to monocomponent insulins, with the sudden reduction of insulin dose which often occurs, is well known $[4,5]$. Although the majority of patients in the 1973 to 1976 period underwent transfer to monocomponent insulin, in only 2 out of 14 patients admitted in hypoglycaemia during this period, could the attack be directly attributed to a recent change in treatment. One worrying factor to emerge is that 7 out of a total of 18 admissions from hypoglycaemia over the seven year study period were associated with 
convulsions and all of these have occurred since 1973. Occasional hypoglycaemic attacks may be the current price we have to pay for stricter control of diabetic children which we emphasise in our clinic and which is in accord with the recent recommendations of the American Diabetes Association [6].

Acknowledgement. We wish to thank Mrs. Alison Smith (Diabetic Research Assistant supported by the British Diabetes Association) for her invaluable assistance.

\section{References}

1. Bradley, R. F.: Diabetic ketoacidosis and coma. In: Joslin's diabetes mellitus. Marble, A., White, P., Bradley, R. F., Krall, L. P. (Eds.), pp. 361-416. Philadelphia: Lea \& Febiger 1974

2. Laron, Z.: More on "diabetic control". J. Pediatr. 92, 340-341 (1977)

3. Chance, G. W.: Outpatient management of diabetic children. Br. Med. J. 1969 II, 493-495
4. Andreani, D., Lavicoli, M., Tamburrano, G., Menzinger, G.: Comparative trials with monocomponent (MC) and monospecies (MS) pork insulins in the treatment of diabetes mellitus. Horm. Metab. Res. 6, 447-454 (1974)

5. Griffin, N. K., Smith, M. A., Baum, J. D.: Reduction of insulin dose on changing diabetic children from standard to monocomponent insulin. Arch. Dis. Child. (1979) (in press)

6. Cahill, G. F., Etzwiler, D. D., Freinkel, N.: "Control" and diabetes. N. Engl. J. Med. 294, 1004 (1976)

Received: April 27, 1978

and in revised form: October 4, 1978

Dr. J. Hardie

Department of Paediatrics John Radcliffe Infirmany University of Oxford

Headington

Oxford OX3 9DU, England 